\title{
PROBLEMÁTICAS DE SALUD PÚBLICA: EL CASO DE CONTAMINACIÓN EN LAS AGUAS DEL RÍO CALI (1900-1910)
}

\section{Public Health Problems: The Case of Pollution In the Waters of Cali River (1900 - 1910)}

\author{
VICTORIA ESTELLA MENESES-PARDO1,2 \\ ${ }^{1}$ Licenciada en Historia, Asistente de investigación en el Semillero de investigación en Historia \\ Ambiental ECOHISTORIA. ${ }^{2}$ Estudiante de la Maestría en Desarrollo Sustentable, Universidad del Valle.
}

E-mail: victory0730@gmail.com

\section{Resumen}

Este artículo tiene como propósito mostrar desde una perspectiva histórico-ambiental las principales problemáticas relacionadas con la disponibilidad y el manejo del recurso hídrico en la ciudad de Santiago de Cali a comienzos del siglo XX (1900 - 1910). Se contemplan aspectos relacionados con las prácticas cotidianas de aprovisionamiento de éste recurso empleadas por la población y las distintas obras de infraestructura pública y privada, destacándose principalmente los chorros, las acequias y las pilas que encauzaban el agua para satisfacer la demanda de la población. Se tienen presentes las inadecuadas prácticas de manejo del recurso hídrico, los problemas ligados a la inexistencia de un adecuado sistema de suministro y control de las fuentes de agua, así como las inapropiadas técnicas de desagüe empleadas, las cuales incidieron negativamente en el panorama de la salud de la población caleña de la época. Se vislumbra, de igual manera, cómo durante este período el crecimiento urbano y el incremento demográfico plantearon nuevos retos para la eficaz distribución del preciado líquido a la sociedad.

Palabras claves: Agua, Río Cali, Pilas de agua, Desagües, Contaminación, Enfermedades, Historia ambiental.

\section{Abstract}

This paper aims to show, from a historic environmental perspective, the main problems related to the availability and management of water resources in the city of Santiago de Cali in the early twentieth century (1900-1910). Here I show that everyday aspects of procurement practices used by the population and the various works of public and private infrastructure created for providing this resource, mainly highlighting the jets, the canals and the batteries it could channel the water will be contemplated to meet demand population. Inadequate practices of water resource management will present the problems linked to the lack of an adequate system of supply and control of water sources, and inappropriate drainage techniques employed, which negatively affected the picture of health Cali population of the time. Looms equally, how during this period the urban growth and population growth, set new challenges for the effective distribution of the precious liquid to society.

Keywords: Water, Cali River, Basins of water, Sewage, Pollution, Disease, Environmental history. 


\section{INTRODUCCIÓN}

En la actualidad el medio ambiente se ha visto seriamente afectado por toda una serie de efectos negativos generados principalmente por la acción antrópica, la cual se refleja en serios problemas que han conducido a la crisis ecológica más importante ocurrida en la historia. Los recursos naturales se han explotado de una manera intensiva y errónea, generando un desequilibrio medioambiental que afecta no sólo a la naturaleza, sino también al ser humano y los demás seres del planeta. La contaminación, por ejemplo, es uno de los graves factores que se desprende de este inadecuado accionar del ser humano frente al uso de la naturaleza.

Uno de los recursos fundamentales para la vida es el agua. Ésta constituye un elemento vital para la sobrevivencia de todos los seres, representa además el recurso estratégico para el desarrollo económico en sus diferentes campos de acción y la satisfacción de toda clase de necesidades. Sin embargo, es un recurso que desde hace ya bastantes décadas ha sido objeto de múltiples abusos representados en acciones de contaminación y extracción intensiva, que han llevado a limitar de forma preocupante el acceso a este recurso vital.

Hacer referencia al agua como recurso fundamental en la vida de los seres humanos y como elemento que ha contribuido a la consolidación de su historia, resulta fundamental. Desde la mirada de la historia ambiental, el estudio del agua, visto desde el plano local, circunscrito para este caso en el ámbito de la sociedad caleña de comienzos del siglo XX, permite evidenciar los diversos problemas que sobre este recurso se generaron en esta ciudad.

Es menester recordar que durante este período la ciudad comenzó a configurar nuevas dinámicas espaciales y situaciones de progreso que se vieron representados en avances logrados en materia de infraestructura urbana. No obstante, en medio de la consolidación de una infraestructura adecuada que sustentara el ofrecimiento de servicios sociales básicos, se dio lugar a una serie de emergencias de insalubridad representadas en la impotabilidad del agua debido a la contaminación registrada por desagües y por los malos usos de este importante recurso que iba en desmedro de la población creciente en la ciudad.

Los efectos negativos causados por las indebidas acciones con relación al uso del agua no se harían esperar, el vertido de aguas sucias de los excusados al Río Cali dieron origen a difíciles situaciones de contaminación, siendo ésta el fiel reflejo de la carencia de una cultura de buen manejo frente a los recursos hídricos, expresada de manera más preocupante en las alarmas de insalubridad que afectó a la población durante la primera década del siglo XX.
La reconstrucción del panorama histórico alrededor de esta temática fue posible gracias a la búsqueda y revisión de fuentes históricas contenidas en folios correspondientes al Fondo Concejo del Archivo Histórico de Cali. Se efectuó un proceso de catalogación de 1911 folios, ubicados precisamente a finales del siglo XIX y primeras décadas del siglo XX. El objetivo de este estudio es dar a conocer las inadecuadas prácticas del las fuentes de agua que dieron lugar a una contaminación emergente en las aguas del Río Cali que incrementaron los problemas de salud pública en la ciudad durante la primera década del Siglo XX.

\section{LA HISTORIA AMBIENTAL: UN ENFOQUE INTEGRADOR ENTRE EL MEDIO NATURAL $Y$ HUMANO}

Este estudio se desarrolla bajo los lineamientos de la Historia Ambiental para explicar las transformaciones del ser humano en relación con su naturaleza y sociedad; evidenciando posiciones sociales, descripción de lugares geográficos junto con los efectos evolutivos o involutivos del medio ambiente. La historia ambiental como la presenta Worster (2004), nos dice que es un instrumento de idealizar, de pensarse científicamente el medio natural.

No basta con la capacidad técnica. Necesitamos pensar de manera profunda sobre nuestro lugar en la naturaleza, y necesitamos llevar a cabo ese pensar con la ayuda de la historia y de las humanidades. (...)Mi tercer argumento consiste en que la historia ambiental puede ofrecernos un conocimiento más profundo de nuestra cultura y nuestras instituciones económicas y de las consecuencias de la mismas para la Tierra. Una de las ideas más difíciles de aprehender es la de que los problemas ambientales podrían tener causas económicas tan profundas como complicadas (Worster 2004).

Así mismo, para conocer las principales particularidades de la utilización y abastecimiento del agua, es necesario acudir al enfoque histórico-ecológico mediante el cual se vislumbre la importancia de los estudios ambientales en la sociedad y cómo se trabaja a partir de la historia.

La historia ambiental se perfila como un campo de investigación, que a lo largo de su trayecto se ha configurado tanto a nivel mundial como latinoamericano. Además cuenta con la importancia interdisciplinar para suplir sus investigaciones referentes al medio natural y humano. Son varios los autores quienes contribuyen a los avances de la historia ambiental en Colombia, algunos como Astrid Ullua, Stefania Gallini (2009) y Aceneth Perafán (2012a), entre otros, 
son quienes hacen la invitación a la realización de estudios históricos ambientales en nuestro país, trabajando unánimamente con autores latinoamericanos como Pablo Camus y Guillermo Castro Herrera, que siguen los postulados de Donal Worster, Manuel González de Molina (1993) y John McNeill (2005), quienes sostienen la postura del historiador frente a la dualidad humano-naturaleza, en la comprensión de cómo los humanos han sido afectados por su ambiente natural a lo largo del tiempo, y cómo ellos han impactado al ambiente y con qué resultados (Camus 2001). Acentuando de manera especial en las transformaciones del espacio y la concepción sobre territorio.

\section{LA CIUDAD DE CALI DURANTE LA PRIMERA DÉCADA DEL SIGLO XX}

La ciudad de Cali a comienzos del siglo XX se caracterizó por varios cambios que generaron distintas dinámicas económicas, sociales y estructurales, las cuales la adentraron paulatinamente en los márgenes de una densidad poblacional más alta y un entorno urbano distinto.

Al finalizar el siglo XIX, la ciudad se componía de espacios que aún hacían alusión a viejas estructuras sociales. De hecho, a partir del nuevo siglo se empezó a generar nuevos imaginarios sobre decoración y ornamentación de la ciudad, principalmente en los parques y sitios públicos.

A medida que se fue incrementando la población, la ciudad se vio obligada a expandir sus terrenos, posibilitando opciones de vivienda, cultivo y negociación de tierras. De manera que la ciudad pequeña y con poca población se ve rodeada por nuevos rumbos de progreso urbano y económico, que invitan a la afluencia de distintas personas a la ciudad, desde inmigrantes extranjeros, hasta personas nacionales de otras ciudades o villas, que llegan a Cali con el furor de lo urbano, las expectativas por el cambio y las nuevas oportunidades. Este periodo fue caracterizado como un proceso a gran escala de inmigración en la ciudad. Se evidenció en primera instancia un aumento como lo asegura Valdivia (1993), de la planta física, duplicada en los primeros años, que van aproximadamente desde 1905 hasta 1912. Según Valdivia, para 1905 la planta física era ocupada por 100 has, mientras que en 1912 ya serían 200 has ocupadas. Los motivos de este aumento poblacional y de ocupación espacial se deben a razones de inmigración y apropiación de terrenos periféricos.

Los barrios que representaban a la ciudad dividían el casco urbano entre sectores de élite y barrios populares.

${ }^{1}$ Para mayor detalle de la descripción de los barrios de la ciudad véase Vásquez (2001).
La ciudad de Cali fue creciendo sobre una suave colina que dominaba la llanura. La parte alta gozó desde un principio, de un clima más fresco que la parte baja. Esta circunstancia determinó que las familias más pudientes edificaran sus casas en la sección comprendida de la calle 12 hacia los collados y de la carrera 10 hacia el río (...) Buscaron ellos (...) empedrar las calles inmediatas a sus morada (...) esos empedrados de las vías determinaron que el barrio de la Merced y San Antonio se llamara "empedrado" y se distinguieran, muy particularmente, del barrio bajo, llamado "bayano" (Hidalgo 1946). ${ }^{1}$

La expansión urbana es un proceso clave en el avance de la ciudad, porque también establece cambios en los imaginarios y sobre todo en la estructura física y ambiental de ésta. Es necesario destacar que a mayor uso del suelo, mayor es el incremento del uso de los recursos por la gente que llegan a poblar. Sobre todo se siente un desgaste en los ambientes de bosques y un incremento del consumo de las aguas.

Debido al proceso de inmigración en el Valle del Cauca y al aumento de población en la ciudad, las necesidades sobre el ofrecimiento de servicios que debería sostener una urbe, dan lugar al desarrollo de proyectos encaminados a mejorar la infraestructura urbana y comercial en la ciudad. Así pues, entrarían las ideas de progreso en el marco del comercio y en las campañas de embellecimiento de Santiago de Cali.

La importancia del cambio en la infraestructura de la ciudad, nos dice Aprile-Gniset (2010), posibilita la transfiguración de símbolos, advirtiendo un cambio de poder, tal como lo demuestra el sustituir las casas municipales alrededor de la plaza, por tiendas, hospedajes, talleres, farmacias, papelerías pertenecientes a los principales linajes de la ciudad: Los O'Byrne, la Familia de Federico Hormaza, los Zawadsky y Fischer, entre otros representantes.

En este ambiente de modernización ingresa al viejo centro la ideología del progreso con la fundación en 1904 de la Sociedad de Mejoras Públicas por los más destacados voceros de los negocios (...) y con el respaldo de sus propios periódicos, la burguesía comercial introduce la ideología de la modernización mediante "el ornato y el embellecimiento" con el fin de lograr un "cambio de imagen" y "cambiar la cara de la ciudad (April-Gniset 2010).

Los habitantes de las principales ciudades del país se veían aquejados por distintos desórdenes generados especialmente por la falta de una infraestructura urbana estable y en buenas condiciones. Para el caso de la ciudad de Cali, las 
Meneses-Pardo (2014)

problemáticas alrededor de la escasa oferta de servicios públicos urbanos desataron graves anomalías frente a la contaminación en las calles, desagües, suciedad en las aguas y exposición de residuos sólidos sin un tratamiento adecuado, como lo veremos a continuación.

Por lo general, desde finales de la época colonial hasta mediados de siglo XX, la provisión de agua limpia o potable constituyó una gran problemática, dado que las calles eran atravesadas por la antigua modalidad de acequias propiciando un ambiente insalubre, obstaculizando además el avance del tapiado de las calles, produciendo humedad y malos olores.

\section{DISTRIBUCIÓN DE LAS AGUAS DEL RÍO Y CONCESIÓN DE PAJAS DE AGUA EN LAS FUENTES PÚBLICAS}

Para el estudio de la distribución y aprovisionamiento de agua y del acueducto en Cali desde comienzos del siglo XX, se tienen en cuenta varias estructuras físicas que representaron la distribución de agua, acompañado de ciertos símbolos y significados sociales en su trasfondo. Para este caso es pertinente relacionar la ubicación y construcción de pilas de agua en la ciudad (Vásquez 1982).

La sectorización de la pilas de agua expone una estratificación social que se ve reflejada en una subdivisión en lo que comprende a la apropiación y aprovisionamiento del agua. Estas fuentes o pilas se ven fragmentadas entre populares o comunes, y las pilas de casas de familias de élite que determinaron en aquel momento la vida de la ciudad en el marco del desarrollo de las relaciones de poder. El aprovisionamiento de agua también se vio involucrado en las subdivisiones que existieron en la primera década del siglo. Por lo general, las pajas de agua pertenecieron a las personas más pudientes, que a la vez poseían fuentes propias para su abastecimiento, mientras que en las fuentes públicas, las pajas de agua se distribuían según órdenes y concesiones municipales con alto grado de dificultad para su abastecimiento.

El aprovisionamiento de agua en la ciudad era posible gracias a las aguas que proporcionaban el Río Cali, el Río Pichindé y La Nieves junto con sus distintos ramales o vertientes. Con estas aguas para la disposición de los ciudadanos, se crearon distintas fuentes de aprovisionamiento y acequias en las zonas más concurridas según una distancia propia y exigida por el Concejo para una distribución equitativa de las aguas.

Así quedarían distribuidas las distintas pilas de decantación en la ciudad:

\section{Contaminación en el Río Cali (1900-1910)}

Art 20. El Acueducto tendrá en su toma las pilas de decantación que se determinen en el plano y exposición que presentó el Ingeniero Municipal al Concejo. De Santa Rosa al Peñón tendrá una poceta de decantación cada 30 metros. Del Peñón a la Acequia grande una cada 40 metros; de la Acequia grande á [sic] las pilas de Jaime y del Crespo cada 50 metros y de allí en adelante una en cada esquina de la ciudad. (A.H.M.C. Tomo 172. Año 1903, Folios 634 646)

Acerca de las concesiones de pajas de agua para las fuentes o pilas de la ciudad es menester citar el concepto que se tiene de paja de agua y las matrices que se conectan al acueducto público para el aprovisionamiento de dichas fuentes. Según el Art. No 29 y 30 del Acuerdo No 43 de 1903.

Art 29. Entiéndase por una paja de agua una medida de distribución que tiene forma circular, de dos centímetros de diámetro. Las piedras en que van gravadas las pajas de agua se denominan matrices y se fijan en los sitios en donde deban desprenderse los Acueductos seccionales del Acueducto público (A.H.M.C. Tomo 172. Folios 634 - 646).

Art 30. Las matrices del Acueducto serán colocadas a una altura tal sobre el solado del mismo Acueducto, que permita pasar por ellas el agua a que se refiere la medida (A.H.M.C. Tomo 172. Folios 634 - 646).

Estas matrices están construidas en mármol por orden de las autoridades municipales. Igualmente, cada matriz lleva una marca o identificación numeral con el fin de que se reconozcan y se puedan ubicar en los planos del municipio. El abastecimiento de pajas de agua para las pilas no implicó un reparto sustancial a todas las fuentes, surgiendo de esta manera una serie de inconformidades de los habitantes por la falta de este recurso, representadas en peticiones hechas al Concejo de Cali para el mejoramiento del acueducto y concesiones de las pajas de agua para las fuentes.

Por ejemplo, en el año de 1903, los habitantes del barrio de San Nicolás solicitaron constantemente al Concejo de Cali el aumento de pajas de agua en su fuente. En respuesta, el Prefecto de la Provincia sugiere al Presidente del Concejo municipal dar recursos al Fontanero público para poder tener algunos peones trabajando en el aumento del agua en las pilas de Santa Librada y San Nicolás (A.H.M.C. Tomo 172. Año 1903, Folio 532).

El problema de las concesiones y aprovisionamiento de pajas de agua para abastecer las fuentes fue común en varias zonas de la ciudad. En 1910 se registró una petición hecha al Concejo de Cali para que se digne concederle al barrio de San Nicolás doce pajas de agua para dotarlo de tres fuentes públicas con el 
fin de suplir las necesidades de la población: la primera en la intersección de la carrera $4^{\circ}$ con calle 17 , la segunda en esquina carrera $7^{\circ}$ con calle 16 y la tercera en "Barrio Nuevo". La proposición fue unánimemente aprobada por la Junta de Fuentes Públicas de San Nicolás y del Vallano (A.H.M.C. Tomo 187. Año 1903, Folios 256 y 260).

De igual manera, se realizó por tramos la ampliación del acueducto por medio de fuentes o pilas de agua, así como lo presentó el proyecto de Acuerdo No. 46 para la construcción en 1903 de dos fuentes públicas de tres chorros cada una. La primera ubicada en la esquina de la casa que fue del Sr. Alcides Isaacs, llevando como nombre Fuente Isaacs, y la segunda ubicada en la esquina de la casa de la señora Elena Paz que llevaría por nombre de Fuente Ortiz en memoria de Fray Ignacio Ortiz. Sin embargo, se considera pertinente, según el estudio de dichos proyectos, la construcción de la Fuente Isaacs y se desaprueba la construcción de la llamada Fuente Ortiz ya que su ubicación está cerca del Río Cali y los vecinos de esta zona tienen sus propias fuentes (A.H.M.C. Tomo 172. Año 1903, Folios 653 y 660).

La "Fuente Ortiz" no es allí donde deba construirse, por que [sic] el público no y los vecinos no la necesitan, ya por que el río está á [sic] pocas cuadras de distancia, y ya por que los vecinos todos tienen sus fuentes privadas, y además como ese lugar es muy concurrido y eso vendría á [sic] ser un obstáculo (A.H.M.C. Tomo 172. Folio 660).

En 1903 se realizó en Cali una serie de ampliaciones del acueducto con el fin de mejorar el servicio y abastecer más zonas de la ciudad con agua potable. El Concejo de Cali decidió entonces reconstruir íntegramente el acueducto municipal creando nuevos ramales que para la época conformaron lo que el municipio dio por nombre acueducto seccional. El Concejo dejó plasmado en el artículo 16 del Acuerdo No. 43 de 1903, la planeación de este nuevo acueducto.

Según lo anterior, se puede deducir que la ubicación de las pilas y su categorización entre públicas o privadas fija el grado de abastecimiento del agua; además se puede aseverar que las pilas públicas sufrían por lógica un deterioro mayor en su decantación, debido al uso frecuente por parte de muchas personas que se servían de ellas, sumado a la escasez del aprovisionamiento de agua limpia, mientras que las pilas privadas ubicadas en casas de familias acomodadas gozaban de un mejor mantenimiento y aprovisionamiento de pajas de agua debido a que tenían mayor posibilidad de comprarlas o intercambiar artículos por estas y así surtirse de ellas.

\section{LO COTIDIANO EN LAS AGUAS DE CALI}

Los usos del río tienen la característica de una modalidad de ocio debido a las actividades recreacionales en días feriados y familiares, pero también se caracteriza por las prácticas domésticas allí realizadas como lavado de ropa, víveres y animales.

Entre los charcos más renombrados se encontraban el Charco del Burro, el de los Pedrones y Santa Rita. Los usos que los antiguos pobladores de la ciudad le dieron al Río Cali en los cauces que conocemos, ya no son posibles debido sus sequías y a la constante suciedad que se aposenta en estos recursos. Desperdiciando en sí más agua de la que el ser humano necesita, sobre todo contaminando sus cauces, arrojando desperdicios biológicos o en tiempos actuales, vertiendo desechos químicos.

Tal como lo arguye Mejía (2000) en sus estudios sobre la ciudad de Bogotá,

El uso de los ríos estuvo relacionado principalmente con el aprovisionamiento de agua de la ciudad, aunque no toda el agua que se utilizaba en la zona construida era tomada de ellos, pues al interior de la ciudad existían nacimientos que eran transformados en fuentes públicas, (...) también se utilizaron los ríos de la ciudad para construir en sus orillas o cercanías, los baños públicos, establecimientos donde concurrían algunos habitantes a tomar baños completos $y$ pasar un rato de esparcimiento (Mejía 2000).

De acuerdo con Londoño \& Londoño (1989) en su ensayo Vida Diaria en las ciudades colombianas, los baños públicos serían para los habitantes de la ciudad una diversión y no una obligación, como sí lo eran para los casos de las tierras templadas o frías, es por ello que las distintas imágenes de los ríos y grandes charcos en Cali se exaltan como lugares de distracción.

Durante el primer cuarto de siglo las casas no tienen agua corriente ni mucho menos baños. Asearse es un rito de los sábados, bien fuera con agua tirada con una vasija o palangana o en una de las quebradas o ríos que pasan por la ciudad, al menos en aquellas como Medellín y Cali donde el clima lo permite. El baño es considerado más como una diversión que como parte de la rutina diaria (Londoño \& Londoño 1989).

Aunque es cierto que estas prácticas de lo cotidiano en los ríos causaban contaminación en las aguas debido a sus usos inadecuados, la administración municipal trataba de controlar ciertas prácticas, aunque no de manera eficiente ya que la problemática por contagio de enfermedades infecciosas se 
prolongaría hasta mediados del siglo XX.

Art 25. Desde Santa Rita hasta el puente grande del río no podrán lavarse ropas, animales, víveres comestibles $n i$ bañarse las personas hasta después de las 8 am de cada día. Exceptúanse los domingos y días feriados en los cuales pueden permitir la Policía que se bañen siempre que no hubiere causal de infección pública por epidemia resonante en la ciudad (A.H.M.C. Tomo 172. Año 1903, Folios 634 - 646. Art 25).

Lo anterior invita a reconocer la importancia de la normativa municipal para tratar de salvaguardar la integridad y seguridad del acueducto de la época, el cual era custodiado por varios agentes, entre ellos la misma policía que en su labor específica se reconoció como policía de las aguas, quien se destacó por controlar y dar un adecuado uso al goce de las aguas para que no afectaran el beneficio de las gentes, ni del bien común, y el fontanero público reconocido en la época como Juez de aguas, cuya labor fue mantener en buen estado los acueductos seccionales y evitar que cayeran los desagües a las fuentes de agua limpia.

Para esta primera década, los problemas acaecidos por la falta de un buen sistema de aprovisionamiento de agua, dificultaron la vida cotidiana de los habitantes, reflejándose en cuadros endémicos de enfermedades gastrointestinales tales como el tifo y la disentería que aumentaron los índices de mortalidad en la ciudad. Sumado a ello, el poco abastecimiento de agua en las distintas fuentes construidas para proveer de agua constantemente a la población, mediante la implementación del sistema de pilas públicas, condicionó la vida de la gente, generando una desigualdad social debido a la división presente entre quienes poseían pajas de agua y los que no.

\section{CONTAMINACIÓN EN EL AGUA DE CALI. LA PROBLEMÁTICA DE LOS EXCUSADOS Y DESAGÜES}

Graves problemas de contaminación en los cauces del río, como veremos más adelante, fueron las causas principales de la propagación de enfermedades intestinales en la que se destacó la fiebre tifoidea. En ello ha radicado la importancia de los distintos estudios en el acueducto de la ciudad dado que la contaminación de las aguas representó una alta tasa de mortalidad en Cali.

Algunos factores de contaminación en las aguas del Río Cali se atribuyen al mal manejo de los desagües de los excusados los cuales se situaban en las mismas casas que poseían fuentes y pajas de agua potable. Estos excusados pasaban por la revisión del fontanero público, quien era el encargado de la provisión de pajas de agua en las fuentes y de la supervisión del estado del acueducto, además de determinar la limpieza y el estado de los desagües, dado que en ocasiones éstas rozaban con el acueducto de la ciudad, aunque para 1903 estuviese prohibido, según acuerdo No. 43, que los desagües pasaran cerca del acueducto municipal, a no ser que cumplieran con unos requisitos de elaboración y ubicación de los mismos:

Art 36. Ningún albañal o desagüe puede ir sobre el Acueducto principal ni a la par de él, á [sic] menos que pase en tubos de hierro bien remachados y construidos de planchas de 4 milímetros de grueso (A.H.M.C. Tomo 172. Año 1903, Folios 634 - 646. Art 36 y 37).

Art 37. Los caños o acequias que atraviesan por las calles, en los sitios en que pasan por sobre el Acueducto público serán construidos de cal y canto y ladrillo en un espacio de 5 metros longitudinales sobre el Acueducto y grosor mínimo de 15 centímetros. - Este gasto será de cuenta del Municipio. (A.H.M.C. Tomo 172. Folios 634 - 646. Art 36 y 37).

Justamente, en un registro se encuentra el fontanero con la revisión de los excusados de los señores Satizábal Madriñan y Enrique Garcés, reportando al Presidente del Concejo la limpieza y el buen estado en el que se encontrarón (A.H.M.C Tomo 187. Año 1910, Folio 78). Por lo tanto, se podría aseverar que ciertos excusados cumplían con las exigencias que el Concejo estipulaba. Sin embargo, estos no serían los únicos existentes en la ciudad.

Los excusados salían de las casas de familias situadas en las cercanías del Río Cali, por lo cual se dirigían hacia él, vertiéndose las aguas sucias con las del río, contaminándolo y generando la inseguridad de estas aguas para el consumo público. Sin embargo, la ciudad de Cali no sería la excepción de estos malos hábitos con los recursos naturales; en la historia de la humanidad según sus distintas formas de vida social, los recursos naturales, sobre todo el hídrico, han sufrido a nivel global un deterioro por desperdicio y contaminación.

Las ciudades se han enfrentado siempre al problema doble de obtener un agua potable adecuada y retirar o disolver los residuos. El planteamiento más sencillo - arrojarlos en los cursos de agua más cercanos y beber también de ellos- sólo funcionó mientras hubo poca gente y mucha agua. Pronto surgieron en la historia humana métodos más complejos encaminados a separar el agua potable del agua para las basuras (McNeill 2003).

Sin embargo, los excusados que depositarón en el agua del Río Cali desperdicios biológicos, no fueron tratados adecuadamente debido a la precariedad de infraestructura, propia de una naciente ciudad de comienzos de siglo que 
comenzaba a experimentar y a establecer nuevos sistemas de vida para su sociedad.

Aquellos excusados de comienzos del siglo XX pertenecieron a las gentes privilegiadas de la ciudad, ya que la mayoría de las familias caleñas no poseían los recursos para construir sus casas con materiales perdurables y mucho menos para construir excusados.

Así pues para 1906 se reportaron varias quejas y peticiones sobre el problema de desagües frente al Río Cali; algunos de los pobladores más afectados por infecciones serían los habitantes del barrio de San Francisco, quienes solicitaron al Prefecto que realizara una inspección a los excusados sobre la acequia pública. No obstante, se pasa la petición al Concejo y se da conocimiento de que el desagüe del que hablan los vecinos del barrio de San Francisco provenía de la escuela de niñas a cargo de las Hermanas de la Caridad (A.H.M.C. Tomo 181. Año 1906 Folio 139 - 140).

A continuación, se expone el croquis que muestra los desagües que llegaban al Río Cali en el año de 1904 (Figura 1). El croquis de los desagües, que van al Río Cali desde del Peñón al puente de Cali 1904, se presenta en la investigación fragmentado en tres imágenes, en las que se pueden apreciar varios elementos que permiten identificar la dinámica del uso del agua y los efectos contaminantes generados en aquel momento de inicios de siglo.

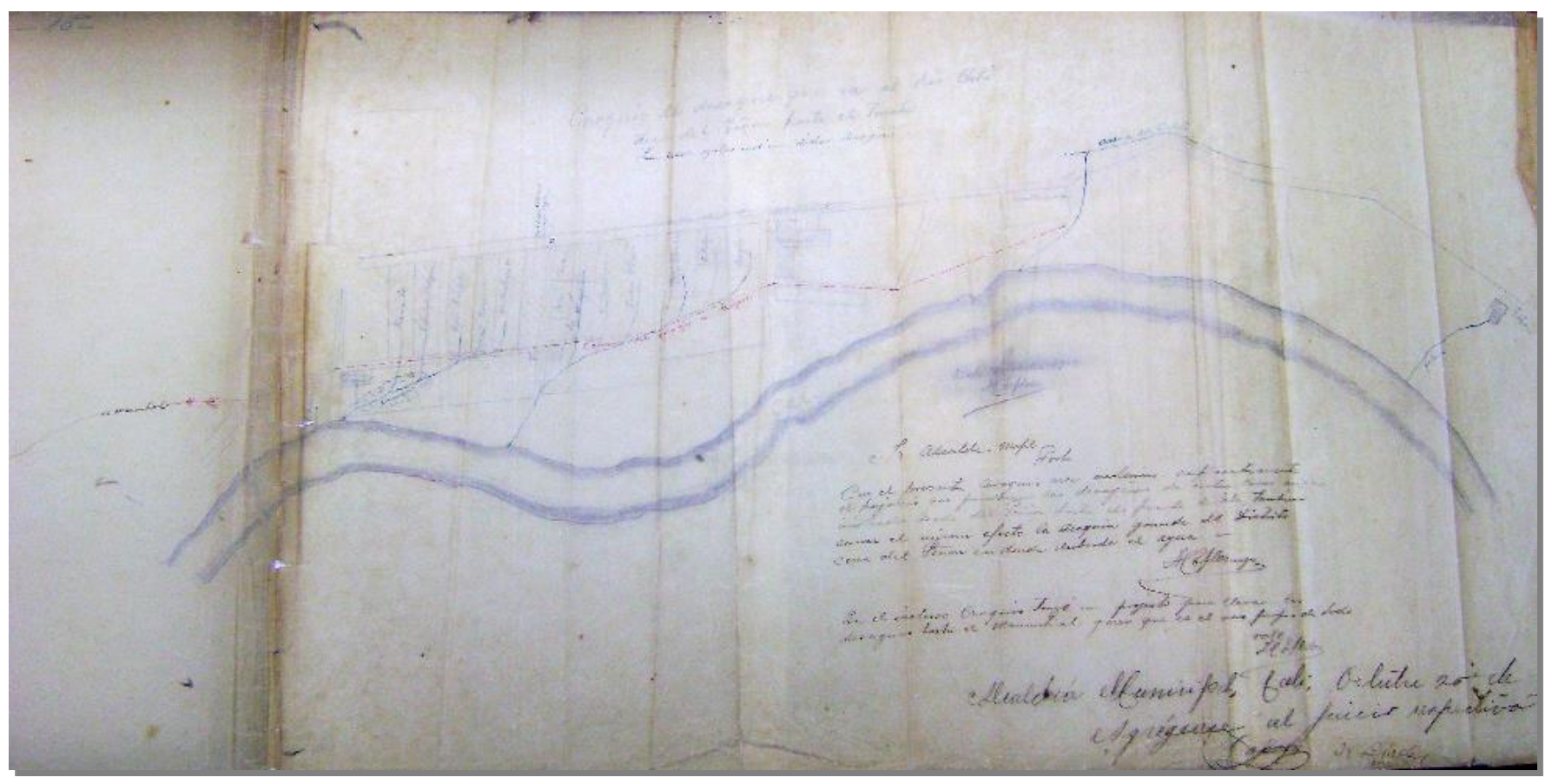

Figura 1. Croquis de los desagües que van al Río Cali desde del Peñón al puente de Cali 1904 (A.H.M.C. Tomo 181. Folios 13 - 15).

La Figura 1, es el plano completo en el cual, se aprecia el trayecto del Río Cali desde el Peñón hasta el puente del Río Cali para 1904. Mientras que la Figura 2, realza los desagües de las casas de familia que se vierten en el río.

La Figura 1 representa la base de la propuesta de desviar los desagües, presentada a la Alcaldía por los señores: Sanchéz, O'byrne y Palacios; peritos reconocedores de los desagües que caían al Río Cali.

Esta comisión denunció al mismo tiempo las alarmas que por mala higiene se presentaban en las aguas del Río Cali:

Desde "El Peñón" hasta las ceibas de "La Ermita" hemos encontrado-caminando por la orilla del río- desagües de letrinas y de otras procedencias (...) las autoridades durante tanto tiempo no hayan puesto remedio á tamaño mal y que las vidas de millones de personas - que habitamos en la Plaza principal pa abajo- estén pendientes de la calidad y cantidad de materias fecales con que un grupo reducido de personas privilegiadas - todas pudientes- nos regalan a diario (A.H.M.C. Tomo 181. Año 1904 Folio 13 v).

De esta manera, se evidencia que los desagües son una razón 
contundente para la contaminación de las aguas y por lo tanto son fuente de insalubridad para la ciudad durante los primeros años del pasado siglo.

El tifo y la disentería que en las formas endémica y epidémica vienen diezmando la población, reconocen por causa principal el desaseo de las aguas del río Cali y la falta de policía que haga la higiene de la ciudad (A.H.M.C. Tomo 181. Año 1904, Folio 14).
En la Figura 2, las líneas azules indican los desagües que salían de las casas de las familias hacia el Río Cali. De igual manera, como se explica, la línea color violeta señala el proyecto de desagüe que llevaría esas aguas hasta el manantial, para ellos una solución, que de igual manera seguiría contaminando un espacio ecológico necesario para la sustentabilidad del mismo río.
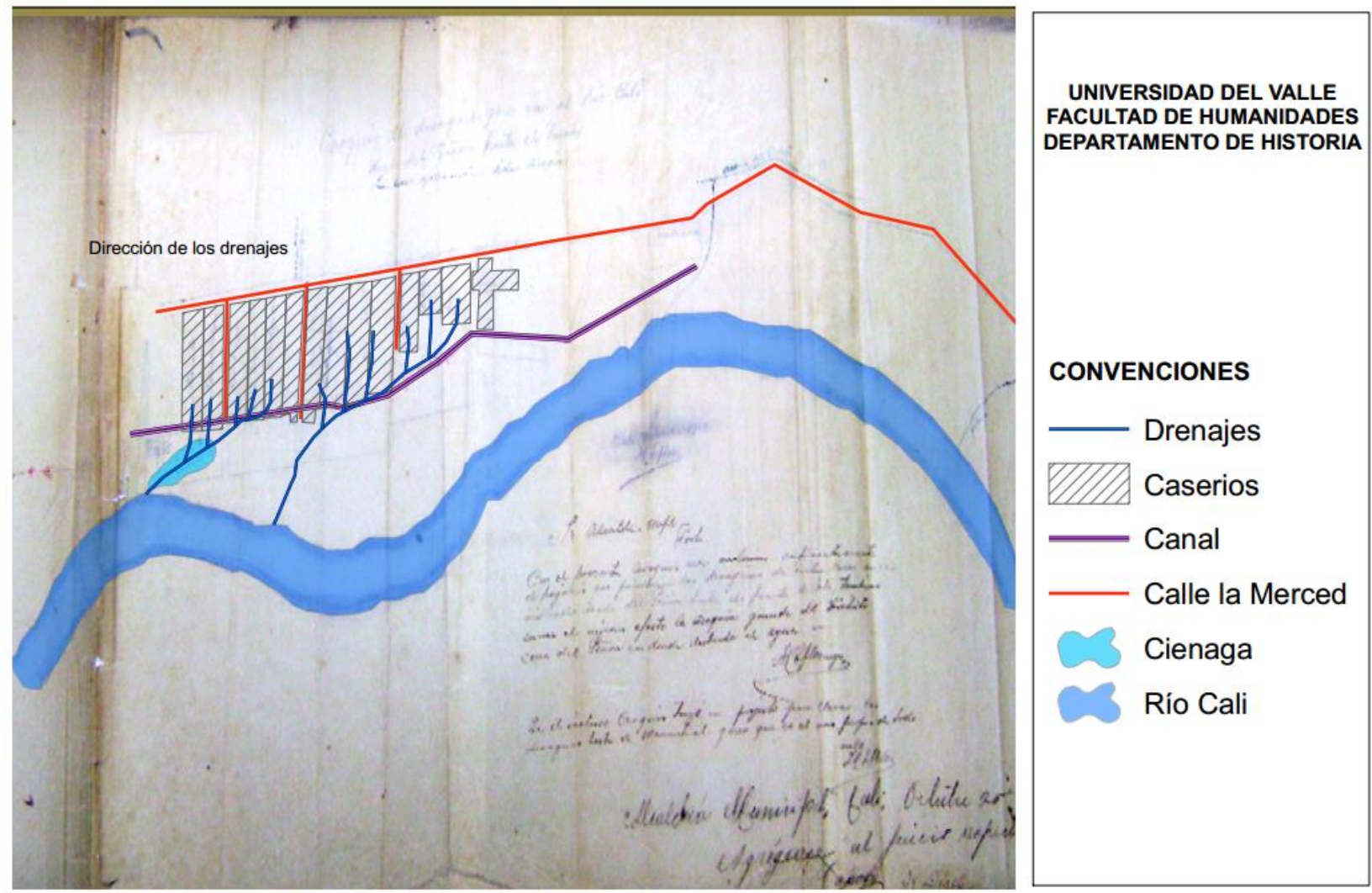

Figura 2. Ilustración de los desagües que van al río. Diseño de colectores para aguas residuales.

Las casas de familia descritas en el croquis, según el mapa expuesto en las Figuras 1 y 2, se describen a continuación: comenzando de izquierda a derecha se encuentran las casas de los señores Sierra, Eduardo Holguín, (sin identificar), C. Borrero, M. Restrepo, Galán, Camacho, Orejuela, V. Romero, Genaro Otero, Rodolfo Sinisterra, (sin identificar) y la iglesia de la Merced, sin obviar las casas de familias ubicadas al extremo de la calle de La Merced, más cercanas al río y a la ciénaga. Igualmente, de izquierda a derecha desde el manantial y cerca del puente se ubica la casa del señor o Familia Lalinde, E. Borrero y José Vásquez, esta última situada contigua a la ciénaga descrita en el croquis.

En la Figura 3 se destacan tres puntos de interés para el análisis, en primer lugar muestra la ubicación de la Acequia grande del Distrito. También la del Peñón y la fábrica allí establecida, de la cual nos ocuparemos más adelante. De la siguiente manera presentan el croquis los peritos encargados de los desagües que van al río:

\section{Sr Alcalde Mpl [sic]}

Con el presente croquis creo aclarar suficientemente el perjuicio que producen los desagües de ciertas casas arriba indicadas desde del Peñón hasta el puente de Cali, también cause el mismo efecto la acequia grande del Distrito cerca del Peñón en donde desborda el agua. En el mismo croquis trazé [sic] un proyecto para llevar los desagües hasta el 
manantial y creo que es el más propio de todos (A.H.M.C. Tomo 181. Año 1904, Folio 13 a 15).

Respecto a la fábrica ubicada en el Peñón, es propio anotar que para 1910 la existencia de la trilladora del Peñón causaba ciertas irregularidades; para entonces el fontanero público el señor David Galindo reporta que dicha fábrica tomaba el agua del cauce público para utilizarla en sus obras. Algo que no era del todo permitido, aun siendo condueño del Acueducto (A.H.M.C. Tomo 187. Año 1910, Folio 75).

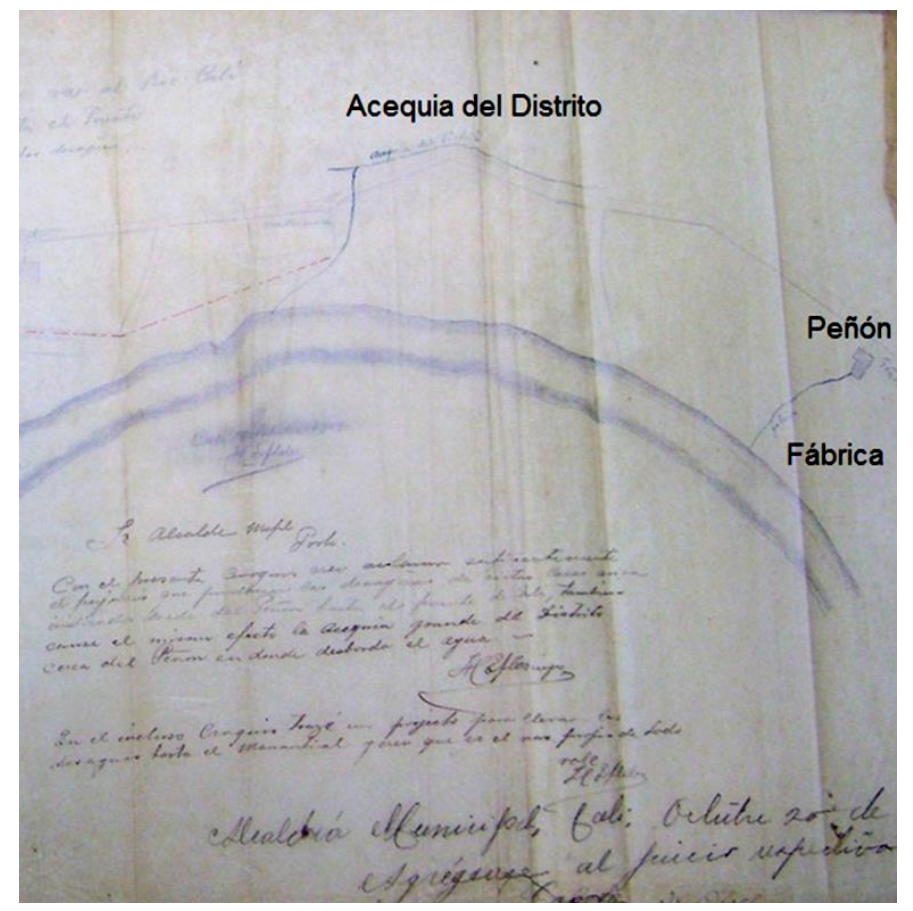

Figura 3. Acequia del distrito y fabrica del Peñón.

\section{CUESTIONES DE SALUBRIDAD PÚBLICA}

Las alarmas de salud pública causaron temor a los habitantes de la época. A este ritmo la contaminación del recurso hídrico elevaría las estadísticas de mortalidad en la ciudad debido a las enfermedades como el tifo y la disentería. De hecho, las quejas por el mal estado del acueducto y de las acequias como ya se ha expuesto, se hacen presentes en distintos testimonios hallados en los registros del Fondo Concejo en el Archivo Histórico de Cali. Hay algunas advertencias como las que hace la sociedad de medicina del Cauca, estableciendo las aguas del Río Cali como impuras e impotables. Asi mismo, existen quejas de ciudadanos exponiendo su preocupación por el abandono de las acequias.

Esta preocupación sobre las infecciones intestinales hizo que el municipio y en especial las corporaciones como el Concejo de
Cali dispusieran aumentar las partidas en el presupuesto de rentas y gastos para las reparaciones del acueducto, la ampliación de sus tramos y el cubrimiento de acequias con lajas de piedra de cantera, acciones que evidencian una preocupación por los asuntos de higiene en la ciudad.

Es claro que la tasa de contaminación reportada en los ríos y surtimientos de agua son el reflejo de un aumento poblacional que a su vez, debido a la llegada de gente nueva en la ciudad, establecieron patrones diferentes de uso y abuso de los recursos, convirtiéndose a largo plazo en perjuicio para los recursos naturales debido a la carencia de control de orden cultural y legal que establezca las razones principales para el cuidado de estos.

Como lo establece la historia ambiental, la evolución de epidemias o calamidades de tipo ambiental en la sociedad son factores producidos por la interacción de los ecosistemas y la relación inequitativa entre la naturaleza y el ser humano en el afán de suplir sus necesidades consumistas que generan el despliegue del progreso en la ciudad.

La historia del medio ambiente reagrupa los temas más antiguos y más nuevos de la historiografía contemporánea: la evolución de epidemias y del clima, dos factores integrantes del ecosistema humano; la serie de calamidades naturales agravadas por la imprevisión o incluso por la absurda buena voluntad de la colonización; la destrucción de la naturaleza, provocada por el desarrollo demográfico o por los predadores del sobreconsumo industrial; los daños de origen urbano e industrial, que conducen a la contaminación del aire o del agua; la obstrucción física, humana o sonora del espacio de las ciudades; y el período de urbanización galopante (Laduire, 1974; citado en Camus, 2001).

De igual manera, no sólo con la falta de equidad en la distribución de los recursos la naturaleza experimenta un notable deterioro; éste también se produce por las indebidas acciones antrópicas entremezcladas con un gran descuido frente al funcionamiento del medio natural. La contaminación en el agua constituye una:

Adición a la misma de materias extrañas e indeseables que deterioran su calidad, la calidad del agua puede definirse como una adecuada aptitud para usos beneficiosos como: bebidas del hombre y los animales, soporte de una vida marina, fluvial y lacustre sana, riego de la tierra y recreación (López 2008).

A parte de los desechos vertidos en el agua, se presentaba otro problema mayor en tiempos de lluvia, pues con las subidas del río se desbordaban además las acequias exponiéndose a toda clase de suciedad, malos olores y bacterias, aumentando las 
enfermedades infectocontagiosas.

Un gran estado de preocupación se presentó en la gente de la ciudad debido a su temor de adquirir infecciones y continuar la lista de muertes por la epidemia que desató la contaminación por materias fecales en el agua de Cali. En varias peticiones señalan la necesidad de mejorar el mal estado de las aguas, solicitando al Concejo generar mayores presupuestos para darle soluciones a este caso y así alejarse de la posible contaminación de tifo.

En una petición del señor Manuel Zorrilla Córdoba, se expone la necesidad de mejorar el acueducto, quejándose del mal estado en el que se encontraba, presentándose una situación de abandono desde la casa del señor Elías Lenis hasta el Peñón, en el sitio de la"Acequia grande"donde el barrizal que se encuentra en el lugar cubre toda la calle, logrando cruzar sólo a caballo, manifestando el temor por ser infectado.

Si es triste ver morir a un pueblo por falta de pan, lo es mucho más verlo agonizar por negligencia ó indiferencia, pudiendo con un poco de buena voluntad salvarlo con la amenaza que tiene a causa de la impureza de las aguas (A.H.M.C. Año 1908 Tomo 185, folios 75 a 77).

Otro reporte se da para el año de 1906 en las orillas del Río Cali por el lado del Vallano, donde la Sociedad de Medicina cataloga sus aguas como impuras e impotables, estimando que por salubridad e higiene los habitantes no obtuvieran aguas provenientes de las orillas del río sino de las fuentes públicas; para este caso recomiendan las fuentes construidas en el Vallano, Pila de Lores, y Pila de San Nicolás, abastecidas de manera recomendada por las aguas del Rio Nuevo (A.H.M.C. Tomo 181. Año 1906, Folios 69 a 71 y 72).

Estas preocupaciones y las necesarias reparaciones del mal estado del acueducto evidencian la urgencia de solucionar la problemática de enfermedades y contagios que desde las aguas se propagaron. A partir de la Constitución de 1886 se crearon políticas sobre salubridad pública del Estado. Es por ello, que se crea La Junta Central de Higiene con la Ley 30 de 1886.

La institucionalización de la política higienista a nivel nacional podría decirse que abarca tres momentos específicos. Una primera fase incipiente de puesta en marcha de las normas higiénicas se ubica entre 1886 y 1920, momento en el que surgieron muchos problemas debido a la resistencia manifestada desde el escenario regional a ser regidos desde el poder central del Estado. Es un momento en el que la consecución del progreso se concibe en relación directa con el desarrollo eficiente de una política higienista (Perafán 2012b).

De acuerdo con la tesis de sociología enfocada en la apropiación de modelos culturales en el proceso higienista relacionado con la transformación de las redes del acueducto en Cali estudiado a partir de las lógicas de la higiene pública, el Concejo Municipal, la Junta de Ornato Público y la sociedad de medicina del Cauca, establece que las enfermedades son entendidas como problemas sociales, es decir, a partir de la interacción de personas y no como causa individual (Velásquez 2007).

Este último punto acerca del control estatal sobre la Higiene pública visto desde lo social consiste como dice Emilio Quevedo "en la dificultad de priorizar las políticas y las acciones sanitarias hacia el problema social y económico nacional, o hacia el asunto del individuo y su comportamiento" (Quevedo 2012).

Tomando como punto de partida el análisis de esta problemática, los efectos y las acciones sociales que priman sobre el comportamiento del individuo son condicionadas por las acciones colectivas y el efecto de los imaginarios existentes en la sociedad.

En conclusion, la ciudad de Cali, entre el periodo de 1900 a 1910, presentó dos problemas. El primero fue un limitado abastecimiento de agua en sus fuentes públicas debido al rápido crecimiento urbano de la época. El segundo fue un deterioro en el Río Cali, su principal fuente hídrica, a causa del vertimiento de excusados por la falta de un adecuado sistema de saneamiento efectivo, que aislara las aguas sucias de las limpias. Esta última generó un estado de insalubridad en la poblacion que alertó a ciudadanos y entidades municipales quienes se preocuparon por mejorar dicha situación, pero que no fue posible sino hasta la contrucción del acueducto metalico en la de década de 1930. No obstante, las denuncias por la contaminación de las aguas del Río Cali, entre otros ríos que pertenecen a este Municipio, siguen siendo pronunciadas, aun en estos tiempos, sin tener una verdadera solución a la contaminación. Puesto que continúa el vertimiento de residuos biológicos, basuras, lixiviados por minería, desagües, entre otros aspectos que condicionan la muerte de los recursos hídricos.

Así pues, los problemas de higiene generados en cualquier parte del mundo debido a la contaminación del agua, niegan la posibilidad de adquirir un derecho fundamental en la vida del ser humano, además de causar un desequilibrio ambiental y ecológico; es por ello que las preocupaciones por recuperar los recursos hídricos entran en las vitales prioridades a solucionar. 


\section{AGRADECIMIENTOS}

Este artículo es resultado del proyecto de investigación desarrollado para obtener el título de Licenciada en Historia, denominado: " $E l$ acceso al agua potable: Un grave problema a resolver en Cali a comienzos del siglo XX (1900 - 1910)" Realizado en el marco de la pasantía de investigación en convenio entre el Archivo Histórico de Cali y el Departamento de Historia de la Universidad del Valle.

\section{REFERENCIAS}

A.H.M.C. Fondo Concejo Año de 1903, Tomo 172. Folios 634 646. Acuerdo No 43 Por el cual se reglamenta el servicio de aguas puras e impuras en el Municipio de Cali.

A.H.M.C. Fondo Concejo.. Tomo 172. Año 1903. Folios 653 y 660. Informe de la comisión para el Proyecto de Acuerdo de la construcción de dos fuentes públicas.

A.H.M.C. Fondo Concejo. Año 1903. Tomo 172. Folios 149 a 151 y 153 a 161 Contratos.

A.H.M.C. Fondo Concejo. Año 1903. Tomo 172. Folio 532.

A.H.M.C. Año de 1906. Tomo 181, folios 69 a 71 y 72.

A.H.M.C. Fondo Concejo. Año 1904. Tomo 181. Folios 13 - 15. Croquis de los desagues [sic] que van al río Cali desde del Peñon [sic] al puente de Cali 1904.

A.H.M.C. Fondo Concejo, Año de 1904, Tomo 181 Folio 13 vuelto.

A.H.M.C. Fondo Concejo, Año de 1904, Tomo 181 Folio 14.

AHMC. Fondo Concejo. Año de 1908. Tomo 185, folios 75 a 77.

A.H.M.C. Fondo Concejo, Año de 1910, Tomo 187 Folio 75.

A.H.MC. Fondo Concejo. Año 1910. Tomo 187. Folios 256 y 260.

A.H.M.C. Fondo Concejo. Año 1910. Tomo 187. Folio 78.

APRIL-GNISET, J. 2010. La ciudad colombiana, Vol. 4. Programa editorial de la Universidad del Valle, Cali. 480 pp.

CAMUS, P. 2001. Perspectiva de La Historia Ambiental: Orígenes, definiciones y problemáticas. Pensamiento Crítico. Revista Electrónica De Historia. (Fecha de acceso 30 enero de 2015); (01) URL disponible en: http://www.pensamientocritico.cl/attachments/074_pcamus-num-1.pdf

GALLINI, S. 2009. Historia, ambiente, política: El camino de la historia ambiental en América Latina. Revista Nómadas (30): 92102.

GONZÁLEZ DE MOLINA, M. 1993. Historia y Medio Ambiente. Editorial Eudema S.A Ediciones de las Universidad Complutense, S.A, Madrid. 96 pp.

HIDALGO, N. 1946. Cali, ciudad conquistadora. Editorial Universidad del Valle, Cali. 199 pp.

LONDOÑO, P. \& LONDOÑO, S.1989. Vida diaria en las ciudades colombianas. En: PLANETA (ed). Nueva historia de Colombia. Vol. 4: 313-320. Editorial Printer Colombiana Ltda. Bogotá.

LÓPEZ, O. 2008. La sustentabilidad urbana, una aproximación a la gestión ambiental en la ciudad. Programa editorial Universidad del Valle, Cali. 117 pp.

McNEILL, J. 2005. Naturaleza y cultura de la Historia ambiental. Revista Nómadas (22): 12-22.

McNEILL, J.2003. Algo nuevo bajo el sol. Historia medioambiental del mundo en el siglo XX. Alianza editoria, España. 504 pp.

MEJÍA, G. 2000. Los años del cambio. Historia urbana de Bogotá 1820- 1910. Centro editorial Javeriano CEJA, Bogotá. 498 pp.

PERAFÁN, A. \& MOTTA, N. 2012a. Historia ambiental del Valle del Cauca, geoespacialidad, cultura y género. Programa editoiral Universidad del Valle, Cali. 199 pp.

PERAFÁN, A. 2012b. El uso del recurso agua en el entorno urbano vallecaucano, a comienzos del siglo XX. Ponencia pronunciada en el VI Simposio de la sociedad caribeña y latinoamericana de historia ambiental. Villa de Leyva, Colombia SOLCHA. 2-14.

QUEVEDO E. 2012. La salud en Colombia. Análisis sociohistórico. Primera parte (Fecha de acceso 25 de enero de 2015) URL disponible en: http://www.saludcolombia.com/actual/salud54/informe.htm

VALDIVIA, L. 1993. Economía y espacio en el Valle del Cauca 1850-1950. Editorial Facultad de Humanidades. Universidad del Valle, Cali. 217 pp.

VÁSQUEZ, E. 2001. Historia de Cali en el siglo 20. Sociedad, economía, cultura y espacio. (Eds) Darío Henao Restrepo y Pacifico Abella, Cali. 318 pp.

VÁSQUEZ, E. 1982. Historia del desarrollo urbano en Cali. Editorial Universidad del Valle, Cali. 217 pp.

VELÁSQUEZ, J. 2007. Transformación de las redes del acueducto 
y nuevos usos del agua. Cali 1900 - 1920. Sobre procesos de apropiación de modelos culturales. Facultad de Ciencias Sociales y Económicas. Departamento de sociología, Universidad del Valle. Santiago de Cali, Colombia.

WORSTER, D. 2004. ¿Por qué necesitamos de la historia ambiental? Revista Tareas (Fecha de acceso 30 de enero de 2015); (117). URL disponible en: http://memoriacentroamericana.ihnca.edu.ni/uploads/media/tareas 117.pdf 